\title{
Hubungan Perilaku Keluarga Sadar Gizi (Kadarzi) Dan Perilaku Hidup Bersih Sehat (PHBS) Dengan Status Gizi Balita 24-59 Bulan
}

\author{
Rizki Amellia ${ }^{1}$, Anggray Duvita Wahyani" ${ }^{* 2}$ \\ ${ }^{1,2}$ Program Studi Ilmu Gizi, Fakultas Ilmu Kesehatan, Universitas Muhadi Setiabudi Brebes, Indonesia \\ e-mail correspondance : anggray.dw@umus.ac.id
}

\begin{abstract}
ABSTRAK
Data profil Dinas Kesehatan Kabupaten Brebes tahun 2018, diketahui hasil Pemantauan Status Gizi (PSG) yaitu dapat diketahui prevalensi balita gizi buruk sebesar 0,25\%, balita gizi kurang sebesar 2,25\%, persentase keluarga berperilaku Kadarzi sebesar $84 \%$ dan persentase rumah tangga berperilaku hidup bersih dan sehat (rumah sehat) sebesar 79\%. Tujuan penelitian ini untuk menganalisis hubungan Perilaku Keluarga Sadar Gizi (KADARZI) dan Perilaku Hidup Bersih Sehat (PHBS) dengan Status Gizi Balita Usia 24-59 Bulan. Desain penelitian observasional analitik dengan desain cross sectional. Jumlah sampel 50 Balita. Pengambilan sampel secara simple random sampling. Uji yang dilakukan Chi-square $(\alpha=0,05)$ dan regresi logistic dengan tingkat kepercayaan (95\%). Intrumen penelitian yang digunakan adalah kuesioner. Hasil penelitian menunjukkan 64\% balita memiliki status gizi kurang, 36\% balita memilliki status gizi baik, $36 \%$ keluarga berperilaku Kadarzi dan 64\%, keluarga berkategori PHBS baik 38\% dan 62\% keluarga kategori PHBS kurang baik. Analisis data menunjukkan ada hubungan signifikan antara perilaku Kadarzi dengan status gizi $(p=0,000, O R=65,34)$. Terdapat hubungan signifikan antara PHBS dengan status gizi $(p=0,000, O R=23,17)$. Ada hubungan yang signifikan perilaku Kadarzi dan PHBS dengan status gizi balita usia 24-59 bulan
\end{abstract}

Kata kunci: Perilaku Kadarzi, Perilaku PHBS, Status Gizi

\section{ABSTRACT}

Brebes District Health Office profile data in 2018, known the results of Nutritional Status Monitoring (PSG) namely can be known the prevalence of malnourished toddlers by $0.25 \%$, malnourished toddlers by $2.25 \%$, the percentage of families behaving Kadarzi by $84 \%$ and the percentage of households behaving clean and healthy (healthy households) by 79\%. The purpose of this study is to analyze the relationship of Nutrition Conscious Family Behavior (KADARZI) and Healthy Clean Living Behavior (PHBS) with The Nutritional Status of Toddlers Aged 24-59 Months. Analytical observational research design with cross sectional design. Sample number 50 Toddlers. Simple random sampling. Tests conducted by Chi-square $(\alpha=0.05)$ and logistic regression with a degree of trust (95\%). The research intrusion used was a questionnaire. The results showed $64 \%$ of toddlers had malnutrition status, $36 \%$ of toddlers had good nutritional status, 36\% of families behaved kadarzi and 64\%, families in the category of PHBS both 38\% and $62 \%$ of families in the PHBS category were less well off. Analysis of the data shows there is a significant relationship between Kadarzi's behavior and nutritional status $(p=0.000, O R=65.34)$. There is a significant relationship between PHBS and nutritional status $(p=0,000, O R=23.17)$. There is a significant relationship of Kadarzi and PHBS behavior with the nutritional status of toddlers aged 24-59 months

Keywords: Kadarzi Behavior, PHBS Behavior, Nutritional Status

\section{PENDAHULUAN}

Status gizi adalah suatu ukuran menegnai kondisi tubuh seseorang yang dapat dlihat dari makanan yang dikonsumsi dan penggunaan zat-zat gizi di dalam tubuh. Status gizi dibagi menjadi 3 kategori, yaitu status gizi kurang, status gizi normal, status gizi lebih [1]. Masa Balita adalah masa kritis atau critical period, karena dapat menimbulkan dampak yang sangat serius, terutama pada periode dua tahun pertama kehidupan, dimana $80 \%$ otak mengalami pertumbuhan yangs 
angat pesat, gangguan gizi yang terjadi pada periode ini bersifat permanen, tidak dapat dipulihkan walaupun kebutuhan gizi pada masa selanjutnya terpenuhi. Balita usia 24-59 bulan dipilih sebagai subjek penelitian dengan pertimbangan: (1) Balita usia 24-59 bulan sangat tinggi intensitas aktivitasnya, (2) pada usia ini mulai terjadi pergeseran status gizi sedang $\mathrm{k}$ gizi kurang. (Almatsier, S. 2005). KADARZI merupakan keluarga yang seluruh anggota keluarganya mengerti,memahami, dan melakukan gizi seimbnag serta mampu mengatasi masalah tersebut. Penilaian status kadarzi didasarkan 5 indikator utama.

PHBS "murni" adalah semua kesehatan yang dilakukan untuk meningkatkan derajat kesehatan agar terhidar dari penyakit yang didalamnya terdapat 13 indikator PHBS yang diambil dari buku Profil Kesehatan Provinsi Jawa Tengan tahun 2015 dikatakan PHBS murni karena beberapa indicator gizi didalam PHBS sudah terdapat dalam variabel KADARZI[2]. Penerapan perilaku hidup bersih dan sehat (PHBS) dimaksudkan untuk mewujudkan rumah tangga serta lingkungan yang sehat [3].

Berdasarkan hasil riset kesehatan dasar (riskesdes) kementerian kesehatan 2018 menunjukan $17,7 \%$ balita masih mengalami masalah gizi. Balita yang mengalami gizi buruk 3,9 $\%$ dan yang menderita gizi kurang sebesar $13,8 \%$, adapun prevelensi balita yang mengalami stunting sebesar 30,8\%, turun dibandingkan hasil riskesdes 2013 sebesar 37,2\% (Riset Kesehatan Dasar (Riskesdes 2018). Data Dinas Kesehatan (Dinkes) Jawa Tengah tahun 2014, menyebutkan bahwa prevelensi gizi kurang pada balita di Jawa Tengah mencapai angka 17,6\%. Data profil Dinas Kesehatan Kabupaten Brebes tahun 2018, diketahui hasil Pemantauan Status Gizi (PSG) dapat diketahui prevalensi balita gizi buruk sebesar $0,25 \%$, balita gizi kurang sebesar 2,25\%, persentase keluarga berperilaku Kadarzi sebesar $84 \%$ dan persentase rumah tangga berperilaku hidup bersih dan sehat (rumah sehat) sebesar 79\%[4].

Penelitian sebelumnya tentang hubungan kadarzi dan PHBS pada tatanan rumah tangga dengan status gizi balita yang telah dilaksanakan oleh Hartono, Bagoes Widjanarko, Mexitalia Setiawati EM (2017) didapatkan hasil bahwa 27,8\% balita memiliki status gizi kurang, 72,2\% keluarga berperilaku kadarzi, dan 70,0\% keluarga berkategori rumah sehat. Menurut penelitian Jayanti dkk (2011) terdapat hubungan positif antara PHBS dengan status gizi balita. Tujuan dalam penelitian ini untuk mempelajari hubungan perilaku hidup sehat dan perilaku keluarga sadar gizi dengan status gizi balita usia 24-59 bulan di desa Songgom Lor, Kecamatan Songgom,Brebes

\section{BAHAN DAN METODE}

Desain Penelitian yang digunakan dalam penelitian ini adalah penelitian observasional analitik dengan metode cross sectional. Penelitian ini dilakukan pada bulan Agustus sampai dengan September 2019. Populasi dalam penelitian ini adalah balita usia 24-59 bulan dan ibu balita di wilayah Desa Songgom Lor, Kecamatan Songgom, Kabupaten Brebes, Jawa Tengah sejumlah 313 balita dan sampel sejumlah 50 balita usia 24-59 bulan dengan pengambilan sampel secara simple random sampling.

Analisi data menggunakan uji hubungan chi-square diperoleh jumlah unit analisis minimal adalah 50 sampel balita yang memenuhi kreteria inklusi, antara lain: balita usia 24-59 bulan yang bertempat tinggal di Desa Songgom Lor Brebes, terdapat data pada KMS atau register posyandu dan tidak sedang sakit saat/selama pengambilan data. Variabel Dependen dalam penelitian ini adalah status gizi balita, variabel Independen adalah pelaksanaan kadarzi dan pelaksanaan PHBS. Data primer diperoleh melalui wawancara dengan menggunakan kuesioner disertai observasi secara langsung yang meliputi pelaksanaan kadrazi, dan pelaksanaan PHBS sedangkan data sekunder yang diperoleh melalui data dari Dinas Kesehatan Brebes dan PuskesmasJatirokeh Kecamatan Songgom.

Alat yang digunakan dalam penelitian ini adalah bol poin, buku, kamera, mikrotoise, timbangan dan bahan yang digunakan adalah kuesioner berisi tentang pernyataan. Penelitian ini dilakukan dengan informasi terperinci yaitu dalam penelitian ini dilakukan dengan cara mengukur tinggi badan balita menggunakan alat mikrotoise dan melukan penimbangan berat badan balita

JIGK Vol. 2, No. 01, Agustus 2020: 18 - 22 
menggunakan timbangan atau dacin, untuk mengetahui status gizi balita dilakukan perhitungan dengan rumus Z-zcore. Untuk mengetahui hasil yang maksimal dilakukan pengukuran, penimbangan, perhitungan sebanyak tiga kali. Analisis statistik yang digunakan Variabel terikat penelitian yaitu status gizi, variabel bebas yaitu perilaku Kadarzi, PHBS, antropometri untuk penelitian status gizi balita. Analisis menggunakan uji che square dengan tingkat kepercayaan $95 \%$.

\section{HASIL DAN PEMBAHASAN}

Tabel 1 Karakteristik Responden

\begin{tabular}{lll}
\hline \multirow{2}{*}{ Karakteristik Responden } & Jumlah & N \\
\cline { 2 - 3 } & & \% \\
\hline Kategori Kadarzi & 18 & 36 \\
Belum Kadarzi & 32 & 64 \\
Kadarzi & & 62 \\
\hline Kategori PHBS & 31 & 38 \\
Kurang Baik & 19 & 64 \\
Baik & & 36 \\
\hline Status Gizi & 32 & \\
Gizi Kurang & 18 & \\
Gizi Baik & & \\
\hline
\end{tabular}

Sumber : Data Primer 2019

Berdasarkan data karakteristik responden pada tabel 1 di atas dapat diketahui bahwa dari 50 responden dengan keluarga yang belum berperilaku Kadarzi berjumlah 18 keluarga (36\%) serta $31(62 \%)$ keluarga dengan perilaku hidup bersih dan sehat berperilaku kurang baik. Status gizi responden diketahui bahwa dari 50 balita, terdapat balita dengan balita berstatus gizi kurang dengan jumlah 32 balita (64\%), dan balita berstatus baik berjumlah 18 balita (36\%).

Tabel 2. Indikator Kadarzi

\begin{tabular}{llllll}
\hline \multirow{2}{*}{ No } & \multirow{2}{*}{ Indikator Kadarzi } & \multicolumn{3}{c}{ Ya } & \multicolumn{3}{c}{ Tidak } \\
\cline { 3 - 6 } & & & $\mathbf{N}$ & $\mathbf{N}$ & $\mathbf{N}$ \\
\cline { 3 - 6 } & & 30 & 60 & 20 & 40 \\
\hline 1 & Menimbang Berat Badan & 38 & 76 & 12 & 24 \\
\hline 2 & Pemberian ASI Eksklusif & 27 & 54 & 23 & 46 \\
\hline 3 & Makan Beraneka Ragam & 28 & 56 & 22 & 44 \\
\hline 4 & Menggunakan Garam Beryodium & 32 & 64 & 18 & 36 \\
\hline 5 & Memberikan Supleman Zat Gizi & & & & \\
\hline
\end{tabular}

Sumber: Data Primer 2019

Berdasarkan table 2 dapat dilihat bahwa indicator kadarzi yang paling sedikit dilaksanakan oleh keluarga kadarzi adalah pada pemberian makanan yang beraneka ragam sebesar 54\%, dan penggunaan garam beryodium sebesar $56 \%$.

Tabel 3. Indikator PHBS

\begin{tabular}{llcccc}
\hline \multirow{2}{*}{ No } & \multirow{2}{*}{ Indikator PHBS } & \multicolumn{4}{c}{ Pelaksanaan PHBS } \\
\cline { 3 - 6 } & & $\mathbf{N}$ & $\mathbf{\%}$ & $\mathbf{N}$ & $\mathbf{\%}$ \\
\cline { 3 - 6 } & & 50 & 100 & 0 & 0 \\
\hline 1 & Persalinan oleh Nakes & 38 & 76 & 12 & 24 \\
\hline 2 & Pemberian ASI Eksklusif & 30 & 60 & 20 & 40 \\
\hline 3 & Penimbangan Berat Bada & 33 & 66 & 17 & 34 \\
\hline 4 & Penggunaan Air Bersih & 19 & 38 & 31 & 62 \\
\hline 5 & Cuci Tangan Pakai Sabun & 29 & 58 & 21 & 42 \\
\hline 6 & Jamban Sehat & 10 & 20 & 40 & 80 \\
\hline 7 & Pemberantas Sarang Nyamuk & 37 & 74 & 13 & 26 \\
\hline 8 & Makan Sayur dan Buah & 16 & 32 & 34 & 68 \\
\hline 9 & Aktivitas Fisik & 10 & 20 & 40 & 80 \\
\hline 10 & Tidak Merokok & & & & \\
\hline
\end{tabular}


Berdasarkan Tabel 3. Dapat dilihat bahwa indicator PHBS yang paling sedikit dilakukan oleh keluarga dengan kategori rumah sehat adalah persalinan yang dibantu oleh tenaga kesehatan sebesar $100 \%$, perilaku tidak merokok sebesar 20\%, dan sebesar 58\% menggunakan jamban sehat dan bersih.

Tabel 4. Hubungan Perilaku Kadarzi dengan Status Gizi

\begin{tabular}{|c|c|c|c|c|c|}
\hline \multirow[b]{2}{*}{ Perilaku Kadarzi } & \multicolumn{2}{|c|}{ Status Gizi } & \multirow{2}{*}{$\begin{array}{c}\text { Total } \\
\text { N }(\%)\end{array}$} & \multirow[b]{2}{*}{ OR } & \multirow[b]{2}{*}{$\mathbf{p}$} \\
\hline & $\begin{array}{c}\text { Gizi Kurang } \\
\mathbf{N}(\%)\end{array}$ & $\begin{array}{c}\text { Gizi Baik } \\
\mathrm{N}(\%)\end{array}$ & & & \\
\hline Belum Kadarzi & 18 & 0 & 18 & 65,34 & $0,000 *$ \\
\hline Kadarzi & 0 & 32 & 32 & & \\
\hline
\end{tabular}

Dari tabel 4 dapat dilihat bahwa hasil tabel silang menunjukkan proporsi balita yang mengalami gizi kurang lebih banyak berasal dari keluarga yang belum berperilaku Kadarzi yaitu 36\% dibandingkan balita dari keluarga yang berperilaku Kadarzi yaitu 64\%. Hasil uji statistik diperoleh nilai $\mathrm{p}=0,000$, yaitu ada nhubungan yang signifikan antara perilaku Kadarzi dengan status gizi balita. Nilai $\mathrm{OR}=65,34$ bermakna keluarga yang belum berperilaku Kadarzi memiliki risiko 65,34 kali lebih besar memiliki balita gizi kurang jika dibandingkan dengan keluarga yang berperilaku Kadarzi.

Pada penelitian ini diketahui adanya hubungan yang signifikan antara perilaku Kadarzi dengan status gizi (Tabel 4). Balita dengan status gizi kurang banyak ditemukan pada keluarga belum kadarzi dibanding dengan keluarga kadarzi. Hal ini menunjukkan bahwa semakin baik keluarga berperilaku Kadarzi, maka akan semakin baik pula status gizi dari balita yang tinggal di dalamnya.

Perilaku Kadarzi sangat penting dalam mewujudkan status gizi baik bagi balita sehingga status gizi sangat berhubungan dengan keluarga sadar gizi. Hasil penelitian terdapat 32 balita yang berstatus gizi baik yang berasal dari keluarga Kadarzi dan 18 balita berstatus gizi kurang yang berasal dari keluarga belum kadarzi. Hal ini disebabkan oleh keseimbangan konsumsi makanan yang adekuat pada balita yang berstatus gizi baik, sedangkan pada balita yang berstatus gizi kurang dipengaruhi oleh konsumsi makanan inadekuat dan penyakit infeksi yang diderita oleh balita. Hal ini sejalan dengan [5] yang mengatakan bahwa faktor penyebab langsung timbulnya masalah gizi pada balita adalah kesesuaian pola konsumsi makanan dengan kebutuhan anak dan penyakit infeksi.

Tabel 5. Hubungan PHBS dengan Status Gizi

\begin{tabular}{|c|c|c|c|c|c|}
\hline \multirow[b]{2}{*}{ PHBS } & \multicolumn{2}{|c|}{ Status Gizi } & \multirow{2}{*}{$\begin{array}{c}\text { Total } \\
\text { N (\%) }\end{array}$} & \multirow[b]{2}{*}{ OR } & \multirow[b]{2}{*}{$\mathbf{p}$} \\
\hline & $\begin{array}{c}\text { Gizi Kurang } \\
\mathbf{N}(\%)\end{array}$ & $\begin{array}{c}\text { Gizi Baik } \\
\mathbf{N}(\%)\end{array}$ & & & \\
\hline Kurang Baik & 13 & 18 & 63 & 23,17 & $0,000 *$ \\
\hline Baik & 0 & 19 & 38 & & \\
\hline
\end{tabular}

Dari tabel 6 dapat dilihat bahwa hasil tabel silang menunjukkan proporsi balita yang mengalami gizi kurang lebih banyak berasal dari keluarga yang berkategori rumah baik yaitu $26 \%$ dibandingkan balita dari keluarga dengan kategori rumah sehat yaitu 36\%. Hasil uji statistik diperoleh nilai $\mathrm{p}=0,000$, yang berarti ada hubungan yang signifikan antara PHBS dengan status gizi balita. Nilai $\mathrm{OR}=23,17$ keluarga dengan kategori rumah tidak sehat memiliki risiko 23,17 kali lebih besar memiliki balita gizi kurang dibanding keluarga dengan kategori rumah sehat.

Pada penelitian ini diketahuai adanya hubungan yang signifikan antara PHBS dengan status gizi (Tabel 5). Hasil penelitian terdapat 19 balita yang berstatus gizi baik yang berasal dari keluarga rumah baik dan 31 balita berstatus gizi kurang yang berasal dari keluarga rumah kurang baik. Hal ini disebabkan karena asupan makan balita cukup sesuai kebutuhan (adekuat), sedangkan, balita yang berstatus gizi kurang dipengaruhi penyakit infeksi yang berbasis lingkungan memang masih merupakan salah satu penyebab kematian di Indonesia. Kematian yang disebabkan oleh penyakit berbasis lingkungan, diantaranya Infeksi Saluran Pernafasan Akut (ISPA), tuberkulosis dan diare. Penyakit berbasis lingkungan dapat menjadi penyebab kematian pada balita.

JIGK Vol. 2, No. 01, Agustus 2020: 18 - 22 
Factor lingkungan berperan besar dalam menentukan derajat kesehatan keluarga, lingkungan tidak hanya sebagai penyebab melainkan juga sebagai penunjang, media transisi, maupun memperberat penyakit yang telah ada [6]. Untuk itu, lingkungan rumah harus senantiasa bersih. Perilaku hidup bersih dan sehat seseorang berhubungan dengan tindakanya dalam memelihara dan meningkatkan status kesehatan dan pencegahan penyakit infeksi antara lain: kebersihan diri, pemilihan makanan sehat dan bergizi, kebersihan lingkungan, penggunakan air bersih yang memenuhi syarat kesehatan dan penggunaan jamban yang sehat serta tidak merokok dalam rumah. Rendahnya status gizi disebabkan oleh berbagai faktor yang saling berkaitan, yaitu: ketersediaan pangan di tingkat rumah tangga, kesehatan lingkungan, status ekonomi dan penyakit infeksi. Perilaku hidup bersih dan sehat merupakan faktor tidak langsung yang menyebabkan penurunan status gizi pada balita

\section{KESIMPULAN}

Berdasarkan penelitian yang dilakukan dapat disimpulkan, bahwa proporsi balita status gizi kurang sebanyak 64\%, dan $36 \%$ balita gizi baik. berdasarkan hasil penelitian bahwa adanya hubungan yang signifikan antara kadarzi dengan status gizi balita dan adanya hubungan yang signifkan antara PHBS dengan status gizi balita.

\section{DAFTAR PUSTAKA}

[1] Almatsier, Jakarta: Penerbit PT Gramedia Pustaka Utama. Baliwati. 2011.

[2] Dinas Kesehatan Jawa Tengah, "Provinsi Jawa Tengah Tahun 2015," Profil Kesehat. Provinsi Jawa Teng., 2015, doi: 10.1016/j.ajo.2008.04.036.

[3] Dinas Kesehatan Jawa Tengah, "Profil Kesehatan Provinsi Jawa Tengah Tahun 2013," 2013. doi: 10.4049/jimmunol.1100709.

[4] Profil kesehatan provinsi jawa tengah tahun 2013, "Profil kesehatan provinsi jawa tengah tahun 2013," Dinas Kesehat. Provinsi Jawa Teng., 2013, doi: 10.4049/jimmunol.1100709.

[5] L. D. Jayanti, Y. H. Effendi, and D. Sukandar, "PERILAKU HIDUP BERSIH DAN SEHAT (PHBS) SERTA PERILAKU GIZI SEIMBANG IBU KAITANNYA DENGAN STATUS GIZI DAN KESEHATAN BALITA DI KABUPATEN BOJONEGORO, JAWA TIMUR," J. Gizi dan Pangan, 2011, doi: 10.25182/jgp.2011.6.3.192-199.

[6] S. Herlina, N. Noriko, A. Hadiansyah, and A. M. Yusuf, "PEMBERDAYAAN MASYARAKAT MELALUI PENINGKATAN PENGETAHUAN, SIKAP, DAN PRAKTIK TERKAIT PERILAKU HIDUP BERSIH DAN SEHAT DI DESA DEWISARI, KECAMATAN RENGASDENGKLOK," J. Pemberdaya. Masy. Univ. Al Azhar Indones., 2020, doi: 10.36722/jpm.v2i2.381. 